\title{
Identification of the Pseudomonas fluorescens group as being responsible for blue pigment on fresh cheese
}

\author{
Conrado Carrascosa, ${ }^{1 *}$ Remigio Martínez, ${ }^{2}$ Esther Sanjuán, ${ }^{1}$ Rafael Millán, ${ }^{1}$ Cristóbal del Rosario-Quintana, ${ }^{3}$ \\ Félix Acosta, ${ }^{4}$ Alfredo García, ${ }^{5}$ and José R. Jaber ${ }^{6}$ \\ ${ }^{1}$ Food Hygiene Unit, Department of Animal Pathology, Animal Production, Bromatology, and Food Technology, Faculty of Veterinary, \\ Universidad de Las Palmas de Gran Canaria, Arucas, 35413 Las Palmas, Spain \\ ${ }^{2}$ Red de Grupos de Investigación en Recursos Faunísticos, Instituto de Biotecnología Ganadera y Cinegética (INBIO), Facultad de Veterinaria, \\ Universidad de Extremadura, 10003 Cáceres, Spain \\ ${ }^{3}$ Microbiology Service, Complejo Hospitalario Materno-Insular de Gran Canaria, Canary Health Service, 35016, Las Palmas de Gran Canaria, \\ Spain \\ ${ }^{4}$ Grupo de Investigación de Acuicultura (GIA), Instituto EcoAqua, Universidad de Las Palmas de Gran Canaria, Spain \\ ${ }^{5}$ Department of Animal Production, CICYTEX-La Orden, 06187 Junta de Extremadura, Spain \\ ${ }^{6}$ Department of Morphology, Faculty of Veterinary, Universidad de Las Palmas de Gran Canaria, Arucas, 35413 Las Palmas, Spain
}

\begin{abstract}
New cases of blue cheese discoloration has led to recent research to identify the causal agent and factors that favor blue pigment appearing. Nonetheless, very few reports have described the source of contamination and the measurements to eradicate the microbiological source on cheese farms by determining the relation between blue discoloration on fresh cheese and the Pseudomonas fluorescens group. Thus, 60 samples from a cheese farm (cheese, equipment surfaces, tap water, and raw and pasteurized milk) were analyzed by phenotypical, MALDI-TOF, $16 \mathrm{~S}$ rRNA sequencing and pulsed-field gel electrophoresis tests to determine the causal agent. The results obtained by pulsed-field gel electrophoresis with restriction enzymes $X b a \mathrm{I}$ and SpeI confirmed tap water as the initial contaminated source. The above-mentioned result was essential to avoid Pseudomonas contamination due to the most residual microorganisms being inactivated through a new disinfection program.

Key words: Pseudomonas fluorescens, cheese farm, fresh cheese, blue pigment, MALDI-TOF, pulsed-field gel electrophoresis
\end{abstract}

\section{INTRODUCTION}

Blue cheese discoloration has been revealed as a major concern because it affects some cheese varieties in different countries. In all cases, the causal agent was Pseudomonas fluorescens (Martin et al., 2011; Nogarol

Received August 24, 2020.

Accepted November 10, 2020.

*Corresponding author: conrado.carrascosa@ulpgc.es et al., 2013; Cenci-Goga et al., 2014; Carrascosa et al., 2015) or other strains of the $P$. fluorescens group (Chierici et al., 2016; Carminati et al., 2019). These bacteria are included in the genus Pseudomonas (gramnegative, rod-shaped and ubiquitous bacteria), imply only a few nutritional requirements, and are described in different environments (soil, decomposing organic matter, atmospheric dust, vegetation, and water), but with a vast variety of animal and plant hosts (Anzai et al., 2000; Frapolli et al., 2007). This group of psychrotrophic Pseudomonas is associated with food deterioration, and has been related to the food trade and hygiene quality (Andreani et al., 2015b).

The special interest shown in the $P$. fluorescens complex and group (Garrido-Sanz et al., 2016) has grown after blue mozzarella occurred. It happened when Italian authorities reported a problem with mozzarella from Germany following consumer complaints in June 2010. They were based on how the product had turned blue after opening the packaging (RASFF, 2011). The microbiological analyses of the blue mozzarella samples revealed a $P$. fluorescens concentration of up to $10^{2}$ cfu/g (Bogdanova et al., 2010). However, the presence of Pseudomonas tolaasii and Pseudomonas libanensis was confirmed, which also produce blue pigment (Chierici et al., 2016). Despite official laboratory analysis and health authorities having related these episodes to the presence of $P$. fluorescens in water, other reports question the relation between the blue color and the presence of the microorganism (Cenci-Goga et al., 2014).

Pseudomonas have been reported in not only these cheese types, but also in other cheeses such as fresh cheese on the Canary Islands (Spain; Carrascosa et al., 2015), fresh Burgos cheese on sale in a Spanish province (del Olmo et al., 2018), or Latin-style fresh cheese in New York (Martin et al., 2011), where contamination 
produced by fluorescent Pseudomonas strains has been described.

Regarding the source of contamination, the majority of blue cheese discoloration cases have reported the water used during the cheese-making process, cleaning water (Carrascosa et al., 2015), or biofilm formation on cheese equipment and pipeline surfaces (Martin et al., 2011). This means that once biofilm forms, Pseudomonas bacteria are more difficult to eliminate by the daily routine of taking hygiene measures for the surfaces that come into contact with raw milk (Ksontini et al., 2013), curd, whey, or cheese. Moreover, other environment elements such as temperature, carbon source, and growth of other bacteria on the medium, can affect the blue pigment production phenomenon (Chierici et al., 2016).

To reduce the frequency of contamination and to eliminate the niche populations for these organisms in food production and processing systems, different identification and tracking methods have been developed (Martin et al., 2011). However, the high genetic and genomic diversity within the $P$. fluorescens complex (Garrido-Sanz et al., 2016) found in cheese samples requires running different phenotypic tests, such as API 20 NE (Martin et al., 2011), MALDI-TOF (Hrabák et al., 2013), and distinct genotypic techniques, such as PCR (Scarpellini et al., 2004; Xu et al., 2017), 16S rRNA sequencing (Caputo et al., 2015; Cenci-Goga et al., 2014; Chierici et al., 2016; Garrido-Sanz et al., 2016), pulsed-field gel electrophoresis (PFGE; Martin et al., 2011; Carrascosa et al., 2015), and MLSA (Andreani et al., 2015a,b; Gomila et al., 2015; Chierici, 2016; Garrido-Sanz et al., 2016), to avoid making mistakes in their correct identification.

One of the most widespread procedures for phylogenetic testing is $16 \mathrm{~S}$ ribosomal RNA, which is based on a small ribosomal subunit sequence. Nonetheless, this procedure is controversial for either its poor resolution when similarly related bacteria are identified (Fox et al., 1992) or recombination and lateral gene transfer events (Boucher et al., 2004). For this reason, running a multilocus sequence analysis (MLSA) frequently overcomes the difficulties of $16 \mathrm{~S}$ rRNA-inferred phylogenies (Gevers et al., 2005) and has been reported as a better guarantee than $16 \mathrm{~S}$ rRNA in the genus Pseudomonas (Kämpfer and Glaeser, 2012), in which the sequence of 3 concatenated housekeeping genes $(g y r B$, rpoD, rpoB), along with $16 \mathrm{~S}$ rRNA sequencing, has worked well to provide a suitable phylogeny of the $P$. fluorescens group (Mulet et al., 2012). Therefore, the MLSA tree has established the presence of 14 main groups according to the tree topology (Garrido-Sanz et al., 2016).

Genus Pseudomonas shows different extracellular pigments, and phenazines represent the most important one. A distinctive trait of P. fluorescens and P. aeruginosa is the secretion of soluble pyocyanin pigment (El-fouly et al., 2015), which contributes to its survival and is produced profusely in media with a low iron content. Iron is an essential nutrient for P. fluorescens to grow (Jayaseelan and Ramaswamy, 2014).

Unlike other pigments, such as pyocyanine, pyoverdine, fluorescein, pyorubin and pyomelanin, which are produced by other $P$. fluorescens strains (Andreani et al., 2015b), very few studies are available in the literature on the blue discoloration identified in cheeses. Thus, only the most recent studies have investigated the characteristics of this discoloration on mozzarella cheese contaminated by P. fluorescens strains (Caputo et al., 2015) and have shown the presence of the uncolored parental compound of indigoidine (leuco-indigoidine). It is a blue diazadiphenoquinone pigment (CAS number 2435-59-8; chemical formula: $\mathrm{C}_{10} \mathrm{H}_{8} \mathrm{~N}_{4} \mathrm{O}_{4}$ ) synthesized by different microorganisms. This finding could make indigoidine responsible for mozzarella blue pigment instead of pyocyanine.

The aim of this work was to identify the source of P. fluorescens contamination on a cheese farm and to determine the relation between the blue discoloration onto fresh cheese and the P. fluorescens identified by phenotype and genotype testing. In addition, new detergent and disinfection protocols were implemented to reduce the $P$. fluorescens contamination risk.

\section{MATERIALS AND METHODS}

The collected fresh cheeses were manufactured artisanally on a cheese farm by enzymatic coagulation, and were salted in brine. These cheeses were made from pasteurized goat (60\%) and cow (40\%) milk. Fresh cheese had a shelf life of $12 \mathrm{~d}$, and was hand-packed at $5^{\circ} \mathrm{C}$ in plastic bags. The daily cheese production was $300 \mathrm{~kg} / \mathrm{d}$ using a monitoring clean-in-place system (Hazard Analysis Critical Control Point, HACCP). Several new actions and controls were performed on tap water and cheese farm equipment, such as maintaining chlorine in tap water at $1.5 \mathrm{ppm}$, increasing the water temperature $\left(45^{\circ} \mathrm{C}\right)$ of the initial rinse, using acid foam detergent and peracetic acid on open surfaces, and adding peracetic acid to cleaning in place. Pseudomonas sp. surface controls were also applied as a new weekly routine.

\section{Sample Collection}

Samples were collected in those fresh cheese batches where blue discoloration was identified. This situation had alerted producers about the cheese alteration made 
on the cheese farm a few (5-6) days ago. These first cheeses formed part of the samples retained for the quality controls on the cheese farm.

To isolate and identify the causal agent of blue discoloration in fresh cheese, 60 samples were collected from an artisanal cheese farm located in North Tenerife, Canary Islands (Spain). The identification methodology described by Carrascosa et al. (2015) was applied with some significant variations, such as the MALDITOF test for Pseudomonas identification and collecting samples from equipment surfaces.

Sampling was carried out in 3 different months (January, March, May) when 20 samples were taken each month. Five sample types were tested on 5 occasions: fresh cheese, equipment surface (milk tank, curd vat, table), tap water, raw milk, and pasteurized milk. All the surfaces that came into contact with milk, curd, or cheese were cleaned and disinfected routinely, according to a disinfection program that forms part of a self-monitoring HACCP (Carrascosa et al., 2012). Surface samples were taken by sterile sponges (Nasco Meat Sampling Kit, with $25 \mathrm{~mL}$ buffered peptone water and a Whirl-Pak Speci-Sponge bag, Whirl-Pak, Madison, WI), and represented different cheese making process steps, such as cheese vats, curd vat, table, and raw milk tank. Finally, one additional control by traditional microbiology was carried out to confirm the presence of the $P$. fluorescens group on fresh cheese for 2 more months.

Culture, Identification and Determination of the Blue Phenotype. All the collected samples were analyzed to detect $P$. fluorescens. Cheese samples (25 g) were collected under aseptical conditions. Six serial dilutions were carried out and subsequently pipetted onto a plate of Cetrimide agar (Cultimed, 416256, Barcelona, Spain) following the protocol by Anderson and Pascual, (2000). The raw and pasteurized milk samples $(10 \mathrm{~mL})$ were processed as indicated above. Water was analyzed according to the ISO 16266:2006 protocol by a vacuum pump.

Then samples were cultured on cetrimide agar plates, and the green coloration and the fluorescent yellowgreen coloration in UV light were identified. To obtain isolated colonies, they were sown by streaking on successive cetrimide agar plates. These isolates were cultured on MacConkey agar (Cultimed, 413779) to help identification. P. fluorescens on MacConkey agar showed a negative result (unable to degrade lactose, no color change according to the $\mathrm{pH}$ indicator neutral red), as well as colorless to pink colonies. All the gram stain, catalase + , oxidase,+ H,L medium $+($ Hugh and Leifson, 1953), oxidative + colonies were identified as Pseudomonas group members and were subsequently confirmed by the additional analysis.
All the cheeses were evaluated to determine the blue pigment production by streak plating onto mascarpone agar according to Cantoni et al., (2001), with confirmation after incubation at $4^{\circ} \mathrm{C}$ and $14^{\circ} \mathrm{C}$ in $2 \mathrm{~mL}$ of mozzarella preserving fluid (Chierici et al., 2016). Pure cultures were stored at $-80^{\circ} \mathrm{C}$ in tryptic soy broth with $20 \%$ glycerol (Sigma-Aldrich, St. Louis, MO) until total identification.

The API 20NE system was applied following the manufacturer's instructions, but this was used only during the first sampling. A profile was obtained after 24 to $48 \mathrm{~h}$ of incubation, and only those colonies identified as excellent $(99.9 \%$ identification and a t-value of $0.75)$ or very good species $(99.0 \%$ identification and a t-value of 0.5; Bosshard et al., 2006) were further analyzed. This test was applied only to the January sampling because it was not possible to identify the P. fluorescens group. Therefore, it was not performed during the next sampling.

\section{MALDI-TOF Analyses Identification}

The MALDI-TOF (AutoFlex II system, Brüker Daltonik, Bremen, Germany) was used to categorize bacterial species from direct colonies. This process was followed as previously reported by Seng et al., (2013) and bacterial species were directly identified from one bacterial colony. Each deposit was covered with $2 \mathrm{~mL}$ of matrix solution (saturated $\alpha$-cyano-4-hydroxycinnamic acid in $50 \%$ acetonitrile and $2.5 \%$ trifluoroacetic acid). The MALDI Biotyper 3.0 software (Matsumura et al., 2014) was used to observe the 100 first peaks of each spectrum to our previously updated MALDI-TOF database. Any identification made by MALDI-TOF was classified as follows: (1) an isolate was considered correctly identified at the species level using MALDI-TOF if 2 spectra had scores $\geq 2,000$; (2) uncertain identified isolates at the species level, but accurate classifications at the genus level, including multiple choice in the same genus (scores 1,999-1,700), were classified without doubt by the MALDI-TOF analysis of 2 additional spectra; (3) a posterior MALDI-TOF identification was run with 4 spectra to identify unsatisfied species during the MALDI-TOF period. Only a minor discrimination between 2 species or more was made, including the correct species that required additional tests $(<1,700 ; \mathrm{Li}$ et al., 2014; Seng et al., 2013).

\section{Genotyping}

$16 S$ rRNA Sequencing. An approximate 1,400-bp fragment of the 16S rRNA gene was PCR-amplified using the previously described primers (Lau et al., 2006). The resultant product was sequenced and compared 
with known 16S rRNA gene sequences in GenBank (https://www.ncbi.nlm.nih.gov/genbank/) by the Basic Local Alignment Search Tool (Altschul et al., 1990).

Pulsed-field Gel Electrophoresis. Pulsed-field gel electrophoresis was used to establish any relatedness among the cheese Pseudomonas isolates obtained in all the sample collections, with the water Pseudomonas isolates from the second sampling (March), which were previously identified as $P$. fluorescens by $16 \mathrm{~S}$ rRNA sequencing with blue discoloration on cheese in the laboratory. This unique tap water Pseudomonas isolate was included in the analysis. The PFGE was performed following the standard Centers for Disease Control and Prevention PulseNet protocol for enteric pathogens (Ribot et al., 2006). Briefly, these bacteria were cultured on tryptone soya agar plates overnight at $32^{\circ} \mathrm{C}$. Later they were fixed in 1\% agarose plugs (SeaKem Gold agarose, Cambrex, Rockland, ME), lysed, and washed. Genomic DNA was digested with a primary restriction enzyme (XbaI, Roche Diagnostics, Mannheim, Germany) for $2 \mathrm{~h}$ at $37^{\circ} \mathrm{C}$ following the manufacturer's instructions. A second restriction enzyme (SpeI, Merck KGaA, Darmstadt, Germany) was used to verify that the 2 strains had indistinguishable patterns.

The size separation of the restricted DNA fragments was performed in $1 \%$ agarose gels (Bio-Rad, Hemel Hempstead, UK) in $0.5 \times$ TBE buffer at $14^{\circ} \mathrm{C}$ by the CHEF MAPPER system (Bio-Rad). The obtained images were interpreted with the Info-QuestFP software (Bio-Rad). Isolates were designated distinct PFGE types if any change was observed. A dendogram was generated by Dice coefficient and the unweighted pair group method with arithmetic averages. Therefore, the API 20NE, MALDI-TOF and 16s rRNA sequencing tests were used to confirm the Pseudomonas species isolated from different samples.

\section{RESULTS}

The results of the phenotypic and genotypic identifications are shown in Table 1 . The 60 isolates were obtained from one cheese farm as follows: 15 isolates from each different sampling, such as fresh cheese, surface, raw milk, pasteurized milk, and tap water. Pseudomonas spp. were found in both the spoiled and unspoiled fresh cheese samples, but $P$. fluorescens was detected only in the cheese with blue discoloration and in the tap water from the cheese-making plants (Table 1).

All the collected samples displayed growth on Cetrimide agar, except for the pasteurized milk samples and 16 samples from different surfaces (6 samples from the January sampling, 6 from March, and 6 from May). The first sampling (January) gave the following results on Cetrimide agar: cheese and raw milk $>10^{5} \mathrm{cfu} / \mathrm{g}$, whereas surface and tap water $<10^{3} \mathrm{cfu} / \mathrm{g}$ after $6 \mathrm{~d}$ at $6^{\circ} \mathrm{C}$. However, the next sampling results (March and May) were lower than those in the first sampling. The observation of green fluorescence under UV light on Cetrimide agar demonstrated Pseudomonas spp. in the analyzed samples. The isolates obtained from pure cultures were identified as gram-negative, catalase-positive, and oxidase-positive rods, and were assigned as the $P$. fluorescens complex by API 20NE strips (Table 1). These bacteria showed green fluorescent pigment under UV in mascarpone agar and mozzarella government liquid, but produced no blue pigment on Cetrimide, except for one blue cheese sample collected in January and another one in May. When these bacteria were spread on the fresh cheese stored at $6^{\circ} \mathrm{C}$ for $8 \mathrm{~d}$, only sample numbers $27,31,32 \mathrm{TF}$ (tap water from March), 8TF (blue cheese from January), and 49TF (blue cheese from May) produced blue pigment.

Despite the absence of blue pigment on the Cetrimide plates from the sampled cheeses and surfaces, the counts of these cheeses after opening packaging were $>$ $10^{5} \mathrm{cfu} / \mathrm{g}$ (after storage at $6^{\circ} \mathrm{C}$ for $6 \mathrm{~d}$ ), which suggests postpasteurization contamination.

The identification of the first sampling (January) by API 20NE found that most isolates $9 / 16(56.25 \%)$ were assigned to $P$. fluorescens; $3 / 16$ (18.75) to $P$. aeruginosa, $2 / 16(12.5 \%)$ to $P$. aureofaciens and $2 / 16(12.5 \%)$ to Serratia marcescens. Nonetheless, the identification coincidence (only Pseudomonas) between API 20NE and MALDI TOF was 16/16 (100\%) at the genus level and $3 / 14(21.45 \%)$ at the species level during this sampling (Table 1).

The identification results obtained during the 3 samplings by the MALDI-TOF and 16s ARN tests were as follows: 14 and 20 samples were identified, respectively, as $P$. fluorescens; 5 and 2 samples as $P$. aeruginosa; 6 and 0 samples as Pseudomonas tolaasii; 0 and 7 samples as Pseudomonas gessardii; 3 and 1 samples as Pseudomonas proteolytica; 2 and 0 samples Pseudomonas synxantha; 4 and 0 samples as Pseudomonas libanensis; 3 and 3 samples as Pseudomonas koreensis; 3 and 2 samples as Pseudomonas putida; 1 and 0 samples Pseudomonas lutea; 0 and 1 samples as Pseudomonas protegens; 1 and 1 samples as Pseudomonas chlororaphis; 0 and 2 as Pseudomonas alcaligenes; 0 and 1 samples as Pseudomonas rhodesiae.

In addition, the $16 \mathrm{~S}$ rRNA test was used to confirm the MALDI-TOF identification results by the P. fluorescens complex and group (Garrido-Sanz et al., 2016), whereas this test identified $33.3 \%$ of the similarity range by identical species; $52.7 \%(19.04 \%+33.3 \%)$ of similarity by species, which belonged to the same group; $88.41 \%(35.71 \%+52.7)$ of similarity by species, which belonged to the $P$. fluorescens complex. Finally, 
Carrascosa et al.: PSEUDOMONA FLUORESCENS AND BLUE PIGMENT ON CHEESE

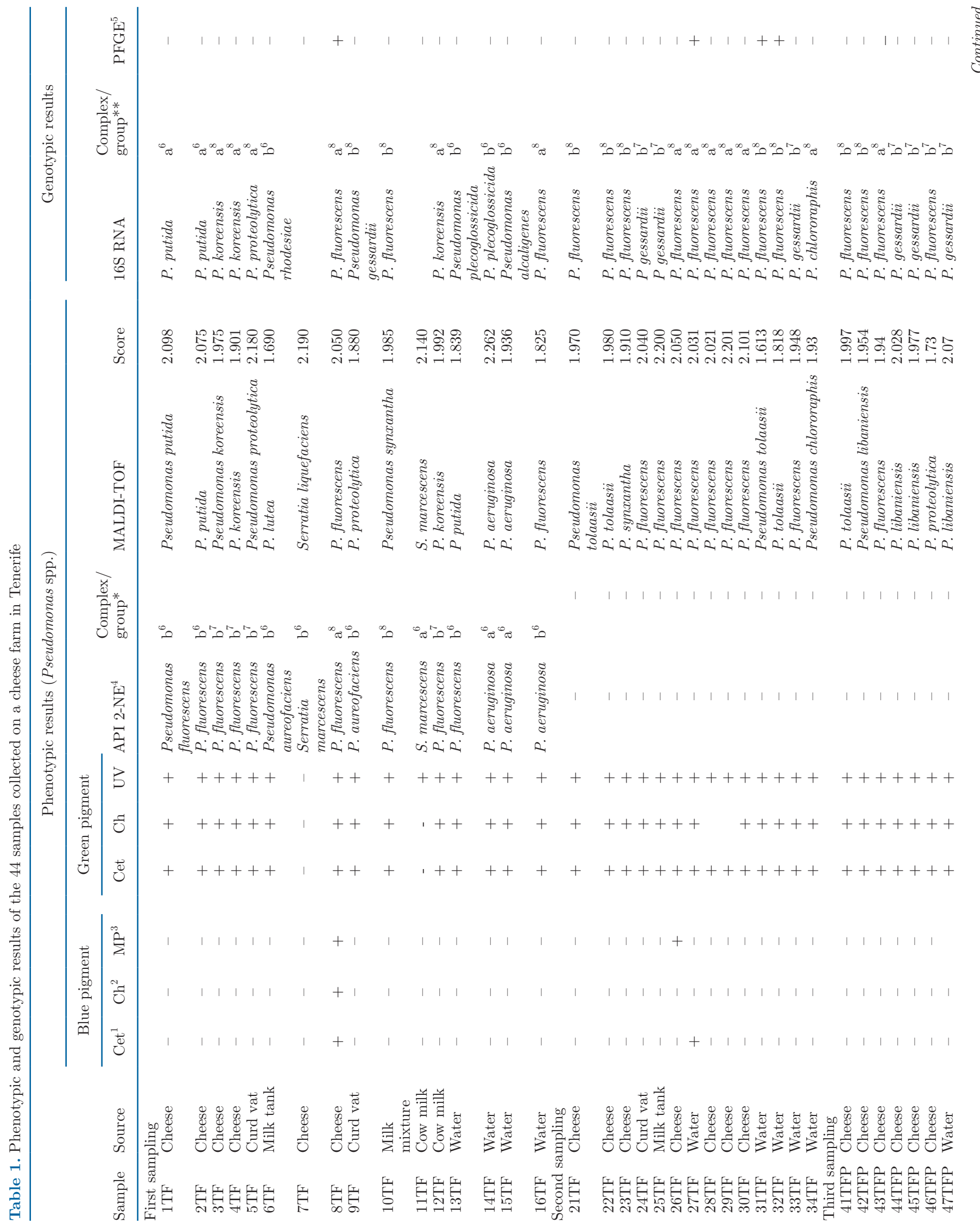




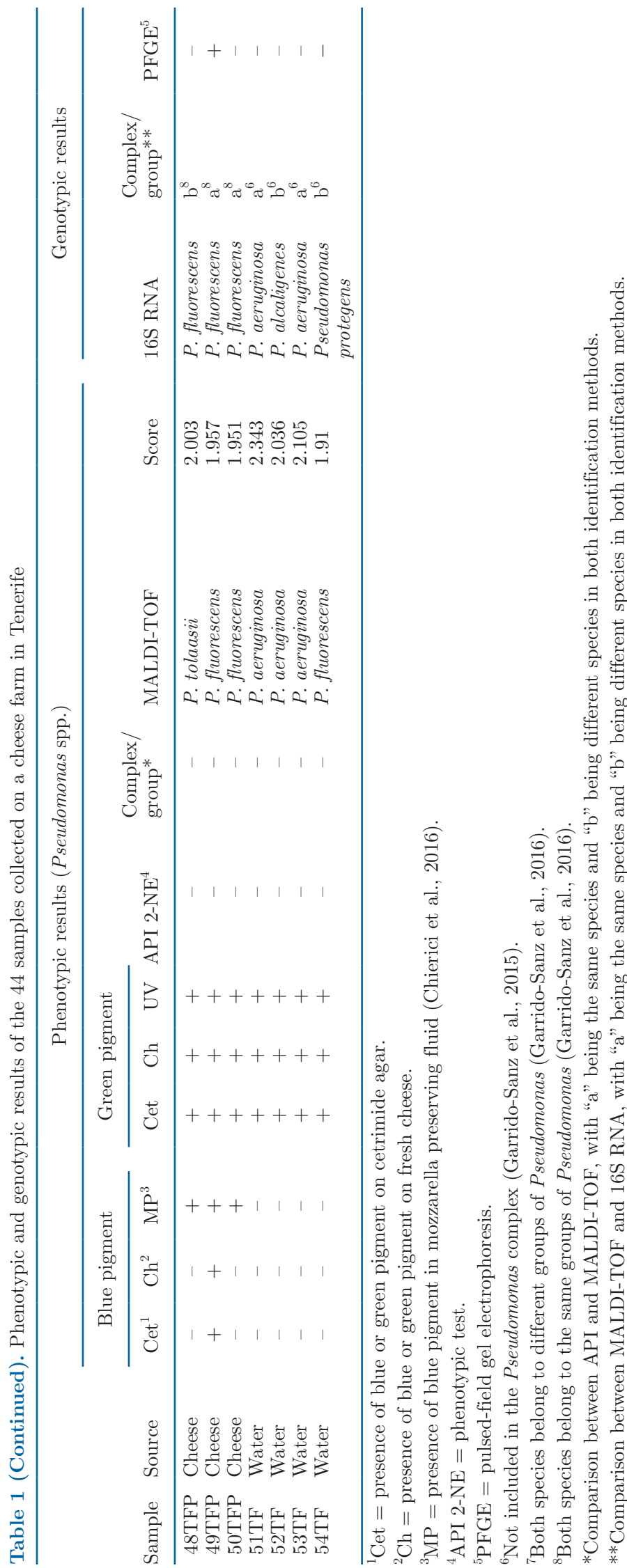

the PFGE test was also run with the 2 isolates from cheese and the other 3 from tap water (Figure 1), which were the only isolates that produced blue pigment on fresh cheese surfaces in the laboratory $(8 \mathrm{TF}, 49 \mathrm{TF}$ and $27,31,32 \mathrm{TF})$. These isolates produced identical patterns, which suggests that they may share a recent common ancestor.

\section{DISCUSSION}

The results obtained herein could explain both the source of environmental contamination and the causative microorganism of the blue discoloration found on a cheese farm in Tenerife.

One of our work objectives was to determine the ability of the phenotypic and MALDI-TOF tests to identify of $P$. fluorescens at the group level. The comparison of both methods provided a coincidence of $42 / 42$ strains $(100 \%)$ at the genus level and poor discrimination at species level 10/20 P. fluorescens strains (50\%). Other clinical microbiology studies have concluded that MALDI TOF is well able to identify a large number of bacteria (Seng et al., 2013) and yeasts (Dhiman et al., 2011), including rare species. Nonetheless, if we merely considered the identified strains to the P. fluorescens complex or at the group level, but not at the species level, we would obtain a coincidence of $37 / 42$ at the complex level, and one of 22/42 at the group level, respectively. These results obtained by a simple protocol (phenotypic test and MALDI-TOF) could be enough to deal with the identification and origin of blue discoloration on cheese farms.

Previous clinical microbiology studies have shown a higher coincidence between MALDI-TOF and $16 \mathrm{~S}$ rRNA. Legarraga et al., (2013) reported a correct identification for $91 \%(245 / 269)$ at the species level and for $95.7 \%(269 / 281)$ at the genus level. Identical results have also been described by Li et al., (2014), who revealed a higher $92 \%$ coincidence at the species level and $94 \%$ at the genus/species level. These results suggest that some factors inherent to aerobic or anaerobic bacteria could exist (Legarraga et al., 2013; Wieser et al., 2012). MALDI-TOFF only includes 20 species of Pseudomonas genus in its database, which could limit its identification ability. Nevertheless, all the species herein identified are included in the database. The MALDI-Biotyper Compass reference library is steadily updated according to precise quality-controlled procedures. Currently, it presents 7,311 reference spectra of 2,509 species from 433 bacteria and fungi genera. The (Bruker) MALDI-TOF MS technology has become a useful instrument for identifying bacteria in the clinical microbiology of laboratories given its accurate, inexpensive and rapid performance efficiencies. 


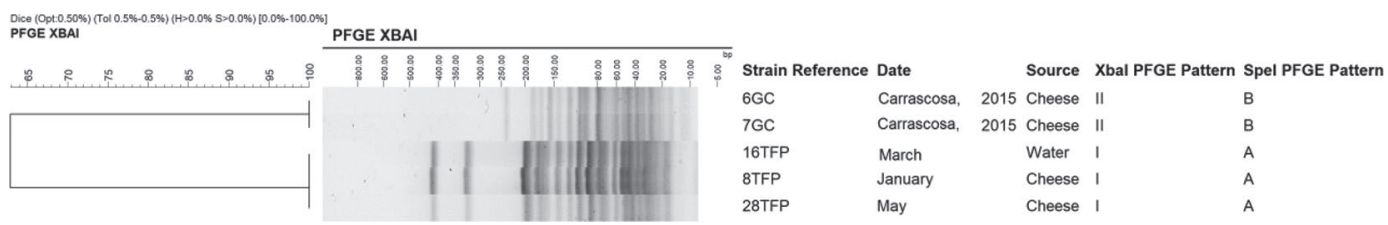

Figure 1. Pulsed-field gel electrophoresis (PFGE) Xbai and Spel results from Tenerife cheese (8TFP, 18TFP), water (16TFP) and Gran Canaria cheese $(6 \mathrm{GC}, 7 \mathrm{GC})$.

Regarding the contamination source, the results of the present study could be compatible with the idea of Nogarol et al. (2013), for whom affected raw samples could be the most believable cause of cross-contami- nation. Hence the contaminated raw milk and water used for cheese production could lead to contaminated working equipment. This last factor was likely the contamination source because Pseudomonas spp. was
Water Control Flowchart

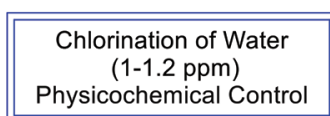

Physicochemical Control 
isolated from the tap water supply network, but not in pasteurized milk. This feature could be explained by the water supplied to the cheese farm being stored in a cistern to which no chlorine was added (assessed level $<0.2 \mathrm{ppm}$ ). By taking in account the relation that links biofilm formation, the discoloration production in $P$. fluorescens strains and the presence of bacteria in food manufacturing environments (Rossi et al., 2018), contaminated water could spread to all equipment surfaces (pipeline, mold, curd vats, tables). In addition, produced biofilms could remain on surfaces for $4 \mathrm{mo}$, and could even survive the cleaning and disinfection plan set up to eliminate Pseudomonas bacteria (Carrascosa et al., 2015). Similar results have been shown for different cheese types (Leriche et al., 2003), in which the source of contamination was traced back to the water supply used for brining cheese. The same applies to fresh Latin-style cheese, where biofilm formation in an agitor track was the source of contamination (Martin et al., 2011)

Finally, the PFGE test revealed that 2 isolates from cheese and 3 from water had identical patterns, which suggests that these isolates shared a recent common ancestor. This could support the hypothesis that tap water might be the main source of contamination. Although numerous $P$. fluorescens strains have already been identified from mozzarella with blue discoloration (Nogarol et al., 2013), the association between $P$. fluorescens strains and mozzarella off-color has not yet been proven. This test showed enough reliability to confirm the relation between Pseudomonas found in water tap and on fresh blue cheese. Therefore, these findings would suggest that tap water without chlorine would be the source of contamination.

In recent years, different studies have worked to shed light on the causal agent and pigment structure that cause blue cheese discoloration (Andreani et al., 2015b; Caputo et al., 2015; Chierici et al., 2016). The first studies indicated that $P$. fluorescens was the main microorganism of color cheese with blue pigment (Cantoni et al., 2001; Martin et al., 2011; del Olmo et al., 2018). Interestingly, current studies have reported that different $P$. fluorescens group species are responsible for blue discoloration in mozarella (Chierici, 2016; Carminati et al., 2019) and that resilient strains P. fluorescens remain in dairy factory environments (Nogarol et al., 2013). This issue might be influenced by different factors, including nutrient availability (Aswathanarayan and Vittal, 2014), growth conditions (Rossi et al., 2016), and the attached surface (Marchand et al., 2012). Other factors such as low incubation temperature have also been found to strongly influence the biofilm formation ability of $P$. fluorescens. In contrast, high temperatures boost adherence capacity. Cenci-Goga et al. (2014) showed that the cold chain did not seem to be a major barrier to grow well in the preservation liquid of mozzarella cheese at refrigeration temperatures.

Finally, a plan was proposed to reduce blue discoloration in fresh cheese and its enormous economic loss (Figure 2). The first measure included increasing the chlorine concentration in tap water to $1.5 \mathrm{ppm}$ as the chloramine gradient reduces the presence of the mixed P. aeruginosa / Klebsiella pneumoniae biofilm (de Beer et al., 1994). This elevation also diminishes phenotypic
A.

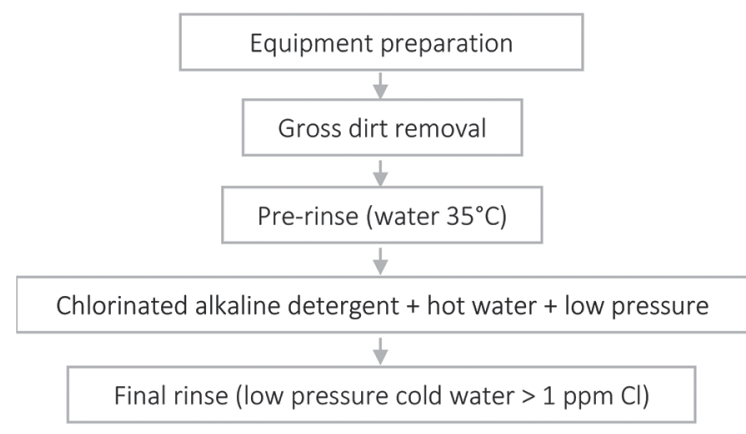

B.

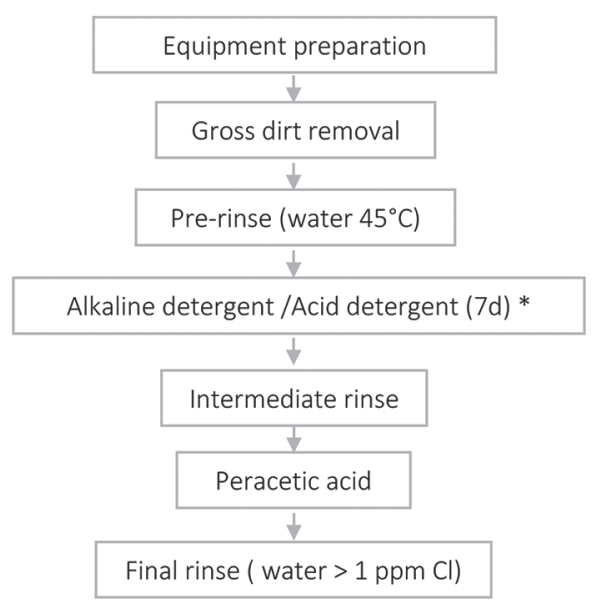

Figure 3. Flowchart showing the previous (A) and new (B) cleaning disinfection procedure of the open surfaces. *Alkaline and acid detergents should be alternatively used. 


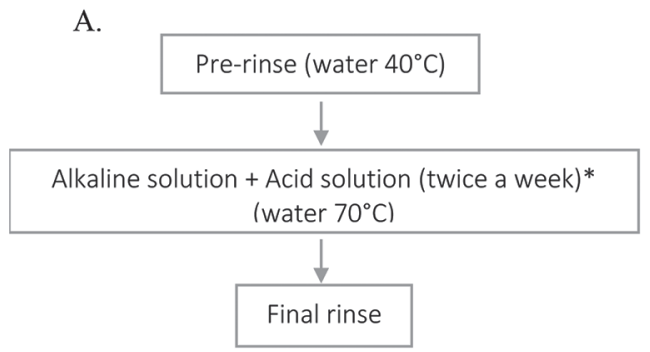

B.

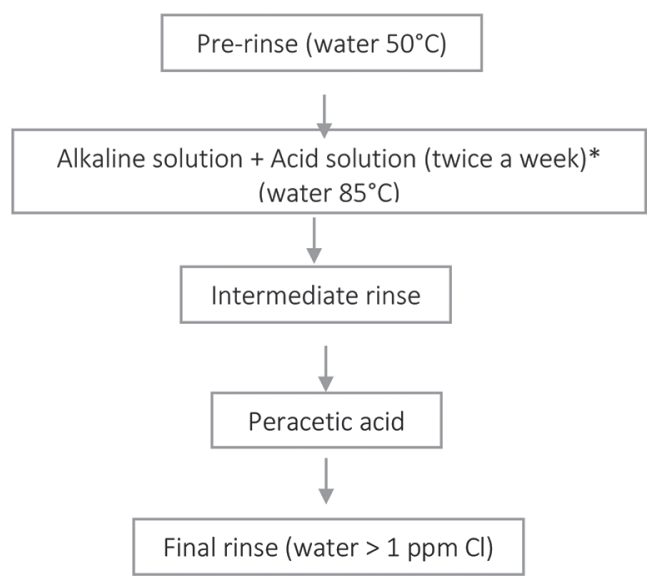

Figure 4. Flowchart showing the cleaning and disinfection procedure of the CIP (clean in place) surfaces. (A) Previous and (B) new cleaning and disinfection program for removing Pseudomonas from milk and curd circuit *Alkaline and acid detergents should be alternatively used.

variation, which leads to biofilm formation and resistance to chlorine, acid, osmotic and oxidative stresses. A new cleaning and disinfection program, composed of an enzymatic detergent (Enzivix 30, Proquimia S.A., Spain), followed by the application of chlorinated alkaline foam detergent-disinfectant and an oxidizing disinfectant based on peracetic acid (Asep 150, Proquimia S.A., Spain), was used on all open surfaces (Figure 3) and clean-in-place surfaces (Figure 4). These measures reduced Pseudomonas spp., and blue cheese discoloration completely disappeared. This plan was essential for reducing biofilm formation as the most residual microorganisms were inactivated through disinfection. Similar recommendations have been made by Verran et al. (2016). Other authors prefer to add a starter culture as a type of hurdle technique to reduce the risk of pathogen growth and spoilage (Martin et al., 2011). Nonetheless in our study, these starter cultures were rejected because they could affect fresh cheese taste, as reported by Carrascosa et al. (2015). To improve the control of Pseudomonas on cheese farms, further microbiology controls, such as pasteurized milk, surfaces, and fresh cheese, were included in the laboratory routine. These results were all negative for the following $2 \mathrm{mo}$.

\section{CONCLUSIONS}

Given the relevance of blue discoloration in mozzarella and fresh cheeses, it is necessary to shed light on the current phenotypical and genotypical features of the P. fluorescens group, the storage conditions of fresh cheeses, and their control on cheese farms. Therefore, the implementation of specific measures for the early detection of Pseudomonas spp. by controls made on surfaces, final products and water should also be included as normal microbiological routines. The application of specific hygiene and disinfection plans would drastically reduce pseudomonas counts and avoid new blue discoloration on fresh cheeses. Maintaining the cold chain does not seem an issue for Pseudomonas spp. contamination; these microorganisms are able to grow well even at refrigeration temperatures, as blue discoloration appears on the first day of contamination. The combination of phenotype and MALDI-TOF tests suitably identified the complex $P$. fluorescens level. Nevertheless, it proved less efficient for determining isolated species, which could be enough to find causal agents and to introduce corrective measures to avoid huge economic losses. Further studies are necessary to determine P. fluorescens behavior on cheese farms and the nature of blue pigment, and to obtain an accurate identification to help to understand the role of this phenomenon and how it can be prevented.

\section{ACKNOWLEDGMENTS}

We are very grateful to the staff at the cheese farm on Tenerife for their support while preparing this paper. We also thank Estrella Gutiérrez, Universidad de Las Palmas de Gran Canaria, for her collaboration. The authors have not stated any conflicts of interest.

\section{REFERENCES}

Altschul, S. F., W. Gish, W. Miller, E. W. Myers, and D. J. Lipman. 1990. Basic local alignment search tool. J. Mol. Biol. 215:403-410. https://doi.org/10.1016/S0022-2836(05)80360-2.

Anderson, M. R. P., and V. C. Pascual. 2000. Microbiología Alimentaria: Metodología Analítica Para Alimentos y Bebidas. 2nd ed. Díaz de Santos, Madrid, Spain.

Andreani, N. A., L. Carraro, M. E. Martino, M. Fondi, L. Fasolato, G. Miotto, M. Magro, F. Vianello, and B. Cardazzo. 2015a. A 
genomic and transcriptomic approach to investigate the blue pigment phenotype in Pseudomonas fluorescens. Int. J. Food Microbiol. 213:88-98. https://doi.org/10.1016/j.ijfoodmicro.2015.05.024.

Andreani, N. A., M. E. Martino, L. Fasolato, L. Carraro, F. Montemurro, R. Mioni, P. Bordin, and B. Cardazzo. 2015b. Reprint of "Tracking the blue: A MLST approach to characterise the Pseudomonas fluorescens group." Food Microbiol. 45:148-158. https://doi .org/10.1016/j.fm.2014.11.011

Anzai, Y., H. Kim, J. Y. Park, H. Wakabayashi, and H. Oyaizu. 2000. Phylogenetic affiliation of the pseudomonads based on 16S rRNA sequence. Int. J. Syst. Evol. Microbiol. 50:1563-1589. https://doi .org/10.1099/00207713-50-4-1563.

Aswathanarayan, J. B., and R. R. Vittal. 2014. Attachment and biofilm formation of Pseudomonas fluorescens PSD4 isolated from a dairy processing line. Food Sci. Biotechnol. 23:1903-1910. https:// doi.org/10.1007/s10068-014-0260-8.

Bogdanova, T., E. M. F. Rodas, S. Greco, R. Tolli, and S. Bilei. 2010. Microbiological investigation of mozzarella samples on the occasion of the blue mozzarella alert. Pages 148-149 in XII Congresso Nazionale S.I.Di.L.V., Genoa, Italy.

Bosshard, P. P., R. Zbinden, S. Abels, B. Böddinghaus, M. Altwegg, and E. C. Böttger. 2006. 16S rRNA gene sequencing versus the API 20 NE system and the VITEK 2 ID-GNB Card for identification of nonfermenting Gram-negative bacteria in the clinical. J. Clin. Microbiol. 44:1359-1366. https://doi.org/10.1128/JCM.44.4 .1359-1366.2006.

Boucher, Y., C. J. Douady, A. K. Sharma, M. Kamekura, and W. F. Doolittle. 2004. Intragenomic heterogeneity and intergenomic recombination among haloarchaeal rRNA genes. J. Bacteriol. 186:3980-3990. https://doi.org/10.1128/JB.186.12.3980-3990 .2004 .

Cantoni, C., S. Stella, B. Ripamonti, and R. Marchese. 2001. Anomalous colouration of mozzarella cheese. Ind. Aliment. 40:33-35.

Caputo, L., L. Quintieri, D. M. Bianchi, L. Decastelli, L. Monaci, A. Visconti, and F. Baruzzi. 2015. Pepsin-digested bovine lactoferrin prevents mozzarella cheese blue discoloration caused by Pseudomonas fluorescens. Food Microbiol. 46:15-24. https://doi.org/10 .1016/j.fm.2014.06.021.

Carminati, D., B. Bonvini, L. Rossetti, M. Zago, F. Tidona, and G. Giraffa. 2019. Investigation on the presence of blue pigmentproducing Pseudomonas strains along a production line of fresh mozzarella cheese. Food Control 100:321-328. https://doi.org/10 .1016/j.foodcont.2019.02.009.

Carrascosa, C., R. Millán, J. R. Jaber, P. Lupiola, C. del RosarioQuintana, C. Mauricio, and E. Sanjuán. 2015. Blue pigment in fresh cheese produced by Pseudomonas fluorescens. Food Control 54:95-102. https://doi.org/10.1016/j.foodcont.2014.12.039.

Carrascosa, C., P. Saavedra, R. Millán, J. R. Jaber, E. Pérez, R. Grau, A. Raposo, C. Mauricio, and E. Sanjuán. 2012. Monitoring of cleanliness and disinfection in dairies: Comparison of traditional microbiological and ATP bioluminescence methods. Food Control 28:368-373. https://doi.org/10.1016/j.foodcont.2012.05.001.

Cenci-Goga, B. T., M. Karama, P. Sechi, M. F. Iulietto, S. Novelli, and S. Mattei. 2014. Evolution under different storage conditions of anomalous blue coloration of Mozzarella cheese intentionally contaminated with a pigment-producing strain of Pseudomonas fluorescens. J. Dairy Sci. 97:6708-6718. https://doi.org/10.3168/ jds.2014-8611.

Chierici, M. 2016. Investigation on the blue phenotype in pseudomonas species involved in blue discoloration defect of fresh cheese. $\mathrm{PhD}$ thesis. Dipartimento di Scienze per gli Alimenti, la Nutrizione e L'ambiente. Università Degli Studi di Milano.

Chierici, M., C. Picozzi, M. G. La Spina, C. Orsi, I. Vigentini, V. Zambrini, and R. Foschino. 2016. Strain diversity of Pseudomonas fluorescens group with potential blue pigment phenotype isolated from dairy products. J. Food Prot. 79:1430-1435. https://doi.org/ 10.4315/0362-028X.JFP-15-589.

de Beer, D., P. Stoodley, F. Roe, and Z. Lewandowski. 1994. Effects of biofilm structures on oxygen distribution and mass transport. Biotechnol. Bioeng. 43:1131-1138. https://doi.org/10.1002/bit .260431118 . del Olmo, A., J. Calzada, and M. Nuñez. 2018. The blue discoloration of fresh cheeses: A worldwide defect associated to specific contamination by Pseudomonas fluorescens. Food Control 86:359-366. https://doi.org/10.1016/j.foodcont.2017.12.001.

Dhiman, N., L. Hall, S. L. Wohlfiel, S. P. Buckwalter, and N. L. Wengenack. 2011. Performance and cost analysis of matrix-assisted laser desorption ionization-time of flight mass spectrometry for routine identification of yeast. J. Clin. Microbiol. 49:1614-1616. https://doi.org/10.1128/JCM.02381-10.

El-Fouly, M. Z., A. M. Sharaf, A. A. M. Shahin, H. A. El-Bialy, and A. M. A. Omara. 2015. Biosynthesis of pyocyanin pigment by Pseudomonas aeruginosa. J. Radiat. Res. Appl. Sci. 8:36-48. https:// doi.org/10.1016/j.jrras.2014.10.007.

Fox, G. E., J. D. Wisotzkey, and P. Jurtshuk. 1992. How close is close: 16S rRNA sequence identity may not be sufficient to guarantee species identity. Int. J. Syst. Bacteriol. 42:166-170. https://doi .org/10.1099/00207713-42-1-166.

Frapolli, M., G. Défago, and Y. Moënne-Loccoz. 2007. Multilocus sequence analysis of biocontrol fluorescent Pseudomonas spp. producing the antifungal compound 2,4-diacetylphloroglucinol. Environ. Microbiol. 9:1939-1955. https://doi.org/10.1111/j.1462-2920 .2007.01310.x

Garrido-Sanz, D., J. P. Meier-Kolthoff, M. Göker, M. Martín, R. Rivilla, and M. Redondo-Nieto. 2016. Genomic and genetic diversity within the Pseudomonas fluoresces complex. PLoS One 11:e0150183. https://doi.org/10.1371/journal.pone.0150183.

Gevers, D., F. M. Cohan, J. G. Lawrence, B. G. Spratt, T. Coenye, E. J. Feil, E. Stackebrandt, Y. Van de Peer, P. Vandamme, F. L. Thompson, and J. Swings. 2005. Opinion: Re-evaluating prokaryotic species. Nat. Rev. Microbiol. 3:733-739. https://doi.org/10 $.1038 /$ nrmicro1236

Gomila, M., A. Peña, M. Mulet, J. Lalucat, and E. García-Valdés. 2015. Phylogenomics and systematics in Pseudomonas. Front. Microbiol. 6:214. https://doi.org/10.3389/fmicb.2015.00214.

Hrabák, J., E. Chudácková, and R. Walková. 2013. Matrix-assisted laser desorption ionization-time of flight (MALDI-TOF) mass spectrometry for detection of antibiotic resistance mechanisms: From research to routine diagnosis. Clin. Microbiol. Rev. 26:103-114. https://doi.org/10.1128/CMR.00058-12.

Hugh, R., and E. Leifson. 1953. The taxonomic significance of fermentative versus oxidative metabolism of carbohydrates by various gram negative bacteria. J. Bacteriol. 66:24-26.

Jayaseelan, S., D. Ramaswamy, and S. Dharmaraj. 2014. Pyocyanin: Production, applications, challenges and new insights. 30:11591168. https://doi.org/10.1007/s11274-013-1552-5.

Kämpfer, P., and S. P. Glaeser. 2012. Prokaryotic taxonomy in the sequencing era - The polyphasic approach revisited. Environ. Microbiol. 14:291-317. https://doi.org/10.1111/j.1462-2920.2011 $.02615 . \mathrm{x}$.

Ksontini, H., F. Kachouri, and M. Hamdi. 2013. Dairy biofilm: Impact of microbial community on raw milk quality. J. Food Qual 36:282-290. https://doi.org/10.1111/jfq.12036.

Lau, S. K. P., P. C. Y. Woo, N. K. H. Li, J. L. L. Teng, K. W. Leung, K. H. L. Ng, T. L. Que, and K. Y. Yuen. 2006. Globicatella bacteraemia identified by $16 \mathrm{~S}$ ribosomal RNA gene sequencing. J. Clin. Pathol. 59:303-307. https://doi.org/10.1136/jcp.2005.028878.

Legarraga, P., M. Moraga, M. Lam, E. Geoffroy, C. Zumarán, and P. García. 2013. Impact of mass spectrometry by MALDI-TOF MS for the rapid identification of aerobic and anaerobic bacteria of clinical importance. Rev. Chilena Infectol. 30:140-146. https://doi .org/10.4067/S0716-10182013000200004.

Leriche, V., R. Briandet, and B. Carpentier. 2003. Ecology of mixed biofilms subjected daily to a chlorinated alkaline solution: spatial distribution of bacterial species suggests a protective effect of one species to another. Environ. Microbiol. 5:64-71. https://doi.org/10 $.1046 / j .1462-2920.2003 .00394 . x$.

Li, Y., B. Gu, G. Liu, W. Xia, K. Fan, Y. Mei, P. Huang, and S. Pan. 2014. MALDI-TOF MS versus VITEK 2 ANC card for identification of anaerobic bacteria. J. Thorac. Dis. 6:517-523. https://doi .org/10.3978/j.issn.2072-1439.2014.02.15. 
Marchand, S., J. de Block, V. de Jonghe, A. Coorevits, M. Heyndrickx, and L. Herman. 2012. Biofilm formation in milk production and processing environments; influence on milk quality and safety. Compr. Rev. Food Sci. Food Saf. 11:133-147. https://doi.org/10 $.1111 /$ j.1541-4337.2011.00183.x.

Martin, N. H., S. C. Murphy, R. D. Ralyea, M. Wiedmann, and K. J. Boor. 2011. When cheese gets the blues: Pseudomonas fluorescens as the causative agent of cheese spoilage. J. Dairy Sci. 94:31763183. https://doi.org/10.3168/jds.2011-4312.

Matsumura, Y., M. Yamamoto, M. Nagao, M. Tanaka, K. Machida, Y. Ito, S. Takakura, and S. Ichiyama. 2014. Detection of extended-spectrum $\beta$-lactamase-producing Escherichia coli ST131 and ST405 clonal groups by matrix-assisted laser desorption ionization-time of flight mass spectrometry. J. Clin. Microbiol. 52:10341040. https://www.doi.org/10.1128/JCM.03196-13.

Mulet, M., M. Gomila, C. Scotta, D. Sánchez, J. Lalucat, and E. García-Valdés. 2012. Concordance between whole-cell matrix-assisted laser-desorption/ionization time-of-flight mass spectrometry and multilocus sequence analysis approaches in species discrimination within the genus Pseudomonas. Syst. Appl. Microbiol. 35:455-464. https://doi.org/10.1016/j.syapm.2012.08.007.

Nogarol, C., P. L. Acutis, D. M. Bianchi, C. Maurella, S. Peletto, S. Gallina, D. Adriano, F. Zuccon, S. Borrello, M. Caramelli, and L. Decastelli. 2013. Molecular characterization of Pseudomonas fluorescens isolates involved in the Italian blue mozzarella event. J. Food Prot. 76:500-504. https://doi.org/10.4315/0362-028X.JFP $-12-312$.

RASFF (Rapid Alert System for Food and Feed). 2011. The Rapid Alert System for Food and Feed (RASFF) Annual Report 2010 Office for Official Publications of the European Communities, Luxembourg.

Ribot, E. M., M. A. Fair, R. Gautom, D. N. Cameron, S. B. Hunter, B. Swaminathan, and T. J. Barrett. 2006. Standardization of pulsedfield gel electrophoresis protocols for the subtyping of Escherichia coli O157:H7, Salmonella, and Shigella for PulseNet. Foodborne Pathog. Dis. 3:59-67. https://doi.org/10.1089/fpd.2006.3.59.
Rossi, C., C. Chaves-López, A. Serio, E. Goffredo, B. T. Cenci Goga, and A. Paparella. 2016. Influence of incubation conditions on biofilm formation by Pseudomonas fluorescens isolated from dairy products and dairy manufacturing plants. Ital. J. Food Saf. 5:5793. https://doi.org/10.4081/ijfs.2016.5793.

Rossi, C., A. Serio, C. Chaves-López, F. Anniballi, B. Auricchio, E. Goffredo, B. T. Cenci-Goga, F. Lista, S. Fillo, and A. Paparella. 2018. Biofilm formation, pigment production and motility in Pseudomonas spp. isolated from the dairy industry. Food Control 86:241-248. https://doi.org/10.1016/j.foodcont.2017.11.018.

Scarpellini, M., L. Franzetti, and A. Galli. 2004. Development of PCR assay to identify Pseudomonas fluorescens and its biotype. FEMS Microbiol. Lett. 236:257-260. https://doi.org/10.1111/j.1574-6968 2004.tb09655.x.

Seng, P., C. Abat, J. M. Rolain, P. Colson, J. C. Lagier, F. Gouriet, P. E. Fournier, M. Drancourt, B. La Scola, and D. Raoult. 2013. Identification of rare pathogenic bacteria in a clinical microbiology laboratory: Impact of matrix-assisted laser desorption ionizationtime of flight mass spectrometry. J. Clin. Microbiol. 51:2182-2194. https://doi.org/10.1128/JCM.00492-13.

Verran, J., B. Carpentier, L. Gram, and C. Mariani. 2016. Factors affecting fouling and cleanability of open food contact surfaces: A report on findings from the EU Integrated Project PathogenCombat. https://www.mmu.ac.uk/media/mmuacuk/content/ documents/rke/A---Factors-affecting-fouling-and-cleanability-of -open-food-contact-surface.ashx.pdf.

Wieser, A., L. Schneider, J. Jung, and S. Schubert. 2012. MALDI-TOF MS in microbiological diagnostics-identification of microorganisms and beyond (mini review). Appl. Microbiol. Biotechnol. 93:965974. https://doi.org/10.1007/s00253-011-3783-4.

Xu, Y., W. Chen, C. You, and Z. Liu. 2017. Development of a multiplex PCR assay for detection of Pseudomonas fluorescens with biofilm formation ability. J. Food Sci. 82:2337-2342. https://doi .org/10.1111/1750-3841.13845. 